\title{
Flap reconstruction of the abdominal wall
}

\author{
Sneha Patel, Alexander F. Mericli, Sahil K. Kapur, Margaret S. Roubaud, Charles E. Butler \\ Department of Plastic Surgery, The University of Texas M.D. Anderson Cancer Center, Houston, TX 77030, USA.
}

Correspondence to: Dr. Alexander F. Mericli, Department of Plastic Surgery, The University of Texas M.D. Anderson Cancer Center, Houston, TX 77030, USA. E-mail: afmericli@mdanderson.org

How to cite this article: Patel S, Mericli AF, Kapur SK, Roubaud MS, Butler CE. Flap reconstruction of the abdominal wall. Plast Aesthet Res 2020;7:18. http://dx.doi.org/10.20517/2347-9264.2019.15

Received: 26 Aug 2019 First Decision: 24 Mar 2020 Revised: 31 Mar 2020 Accepted: 10 Apr 2020 Published: 17 Apr 2020

Science Editor: Raúl González-García Copy Editor: Jing-Wen Zhang Production Editor: Tian Zhang

\begin{abstract}
Large abdominal cutaneous defects may occur in association with complex ventral hernias, trauma, tumor resection, necrotizing infections or septic evisceration. Soft tissue reconstruction of the abdominal wall is performed when there is insufficient adipocutaneous tissue to permit standard, primary closure. A number of reconstructive techniques are available, the choice of which is based on a number of factors, including the size and location of the defect, etiology, and timing of closure. In general, local fasciocutaneous advancement flaps and adjacent tissue rearrangement are the workhorse techniques, followed by regional myocutaneous flaps and free tissue transfers for the most complex and extensive of defects. Herein, we describe our approach to abdominal soft tissue reconstruction, indications, technical nuances, and management of complications.
\end{abstract}

Keywords: Abdominal wall reconstruction, surgical flaps, pedicled flap, free flap, bioprosthetic mesh, hernia, reconstructive surgical procedures

\section{INTRODUCTION}

Abdominal wall defects can occur in association with ventral hernias, trauma, tumors, infections or septic evisceration. The abdominal wall is best conceptualized as a trilaminar structure, with each layer serving a specific purpose: the muscular layer provides dynamic support and function, the fascial layer confers strength and durability, and the skin and subcutaneous tissue serves as a barrier to infection and provides a uniform, aesthetic contour. In abdominal wall reconstruction, each layer must be addressed and repaired to obtain an optimal result. Contemporary methods of abdominal wall reconstruction emphasize synthetic or bioprosthetic mesh for fascial repair and reinforcement, primary myofascial coaptation for a functional, durable and dynamic repair, and a variety of soft tissue flaps and rearrangement techniques to address skin deficits. 
Optimizing skin and soft tissue coverage is of utmost importance in order to reduce the risk of developing a surgical site infection or surgical site occurrences and to expedite recovery ${ }^{[1-3]}$. This is particularly important in the oncologic population, in which a healed wound is imperative prior to initiating adjuvant chemotherapy or radiation therapy. Because the requirement for skin and soft-tissue reconstruction of the abdominal wall intimates adeficiency of local tissue available for resurfacinga defect, most abdominal wall defects are reconstructed using flaps from redundant adjacent tissue in the torso; however, certain cases may require pedicled regional flaps or even free tissue transfer depending on the size of the defect, location, and the patient's body habitus. The reconstructive ladder is a useful framework for guiding abdominal soft tissue reconstruction in most clinical scenarios. However, we have found the M.D. Anderson oncologic abdominal wall reconstruction classification system to be particularly beneficial for the unique needs of the oncologic population $^{[4]}$. At a minimum, planning for abdominal soft tissue reconstruction must take into consideration the defect type, location, and the viability and perfusion of the surrounding tissues. Although a variety of options are available to the reconstructive surgeon for abdominal soft tissue defects, there area number of key points and technical nuances that, when implemented appropriately, can help to ensure an acceptable result with minimal complications.

\section{LOCAL FLAP OPTIONS}

Local flapsinvolve recruiting tissue adjacent to the wound defect. Well-planned incisions and a thorough understanding of the abdominal wall angiosomes is necessary to execute this collection of techniques. Regarding perfusion, local flaps can be designed as having either random-pattern or axial blood supply. There are numerous local flap types, including rotation/advancement, interpolation, V-Y advancement, keystone flaps, propeller flaps, and bipedicled flaps. Most commonly, the flap donor site is closed primarily, however a skin graft can alternatively be employed for this purpose, as in the bipedicled flap.

Pre-existing scars and closure tension are two important factors to consider in local flap reconstruction. For instance, a midline laparotomy scar may preclude designing a local flap along the contralateral abdominal wall. Regarding tension, the area of the local flap that is most important for the reconstruction is also the area that is most vulnerable to reduced perfusion: the most distal point. Reduced perfusion is exacerbated by excessive flap inset tension, therefore it is important to design wide-based, large local flaps, recruiting tissue from areas of relative redundancy, in order to mitigate this possibility. In addition, the thoughtful surgeon should account for expected postoperative edema and abdominal distention in the flap design and inset technique.

A propeller flap is a local fasciocutaneous flap that can be rotated up to 180 degrees in relation to its perforator. Perforator propeller flaps have been well described for extremity and chest wall reconstruction, however their use in abdominal reconstruction is more limited ${ }^{[5]}$. These flaps can be used to cover abdominal defects, recruiting flap tissue from an area with relative adipocutaneous redundancy compared to the recipient site. Propeller flaps are best used for smaller defects, as the donor site should be able to close primarily [Figure 1]. Familiarity with perforator dissection and microsurgical technique is also necessary, which may limit the applicability of this flap type.

A keystone flap is a fasciocutaneous flap composed of two V to Y advancements ${ }^{[6]}$. Unlike most other local flaps, keystone flap mobility is not facilitated by undermining. Instead, undermining should be minimized, in order to keep all underlying cutaneous perforators intact. For any defect, unilateral or bilateral flaps can be designed depending on the size and location of the area of skin deficit. The width of each flap should be at least as wide as the defect and the flap and defect length should be equal. The double VY closures work to advance the flap toward the defect, facilitating a tension-free defect closure. 


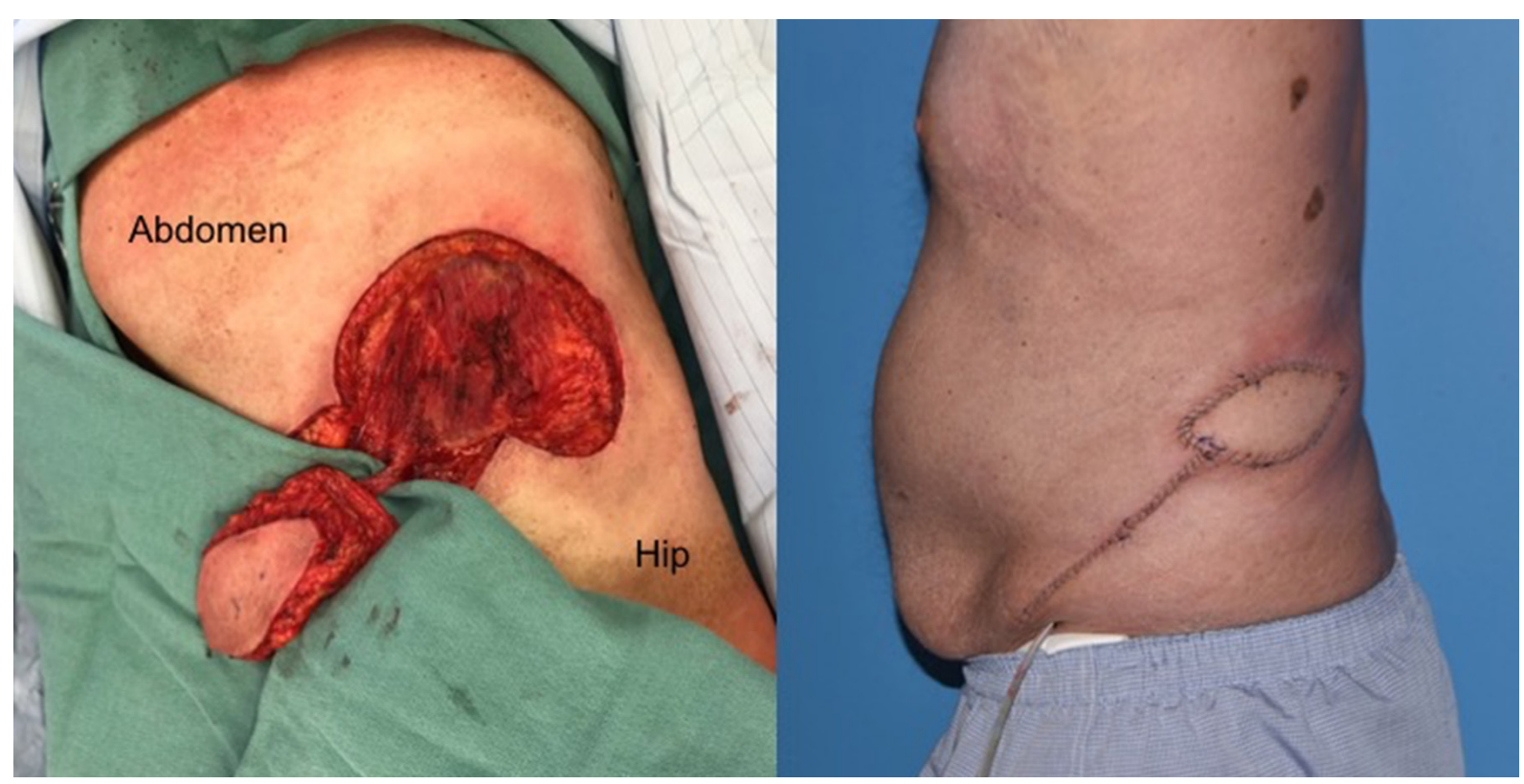

Figure 1. Fasciocutaneousdefect of lateral abdominal wall after resection of an irradiated sarcoma. Reconstructed with fasciocutaneous propeller flap from lumbar segmental perforating vessel

\section{REGIONAL FLAP OPTIONS}

When local tissue is insufficient to fill the defect, a regional flap can be considered. Regional flaps rely on a named blood vessel (pedicle) for perfusion and are commonly harvested from adjacent anatomic areas such as the chest, groin, thigh or contralateral abdomen. They can be designed as a fasciocutaneous, myocutaneous or muscle-only flaps, depending on the defect requirements. Options for reconstruction of the abdominal wall with a regional flap include use of the external oblique muscle ${ }^{[7]}$, tensor fascia lata myocutaneous $(\mathrm{TFL})^{[8,9]}$, rectus abdominis myocutaneous, rectus femoris myocutaneous ${ }^{[10]}$, anterolateral thighfasciocutaneous (ALT) with or without a portion of vastus lateralis muscle ${ }^{[11]}$, latissimus dorsi muscle or myocutaneous and omental flaps ${ }^{[12]}$. Each flap has associated advantages and disadvantages which must be taken into consideration when designing the reconstruction [Table 1].

Since many regional flaps include a muscle, it is important to consider donor morbidity. Although a contralateral rectus abdominis muscle can be used to reconstruct a portion of the abdominal wall, the weakness and hernia potential incurred by moving this muscle may preclude its use. Similarly, the rectus femoris can be used to reconstruct the infraumbilical abdomen, however using this muscle may limit the terminal fifteen degrees of knee extension of the donor leg; this may be acceptable for some patients but not for others. This can be limited or eliminated by performing a tenorrhaphy between the vastus lateralis and medialis tendons superior to the patella. A regional flap's arc of rotation must be carefully measured to ensure it will reach the desired location without pedicle tension. Furthermore, the path the pedicle takes from its origin to the defect location must be planned in order to avoid compression and kinking. If the flap is to be passed through a subcutaneous tunnel from donor site to recipient site, the tunnel must be wide to allow for swelling without pedicle compression. For the pedicled ALT flap, the flap must be passed deep to the rectus femoris and sartorius muscles to allow adequate reach and minimize pedicle compression [Figure 2]. This is critical in preventing compression of the flap or pedicle postoperatively when the patient is mobile and exerting rotational, flexion, and extension forces on the torso.

\section{FREE FLAP OPTIONS}

Free tissue transfer for abdominal wall reconstruction is relatively uncommon, considering the adequate local soft tissue and numerous regional flap options present in most patients. However, in certain clinical 
Table 1. Regional flap options for abdominal wall soft tissue reconstruction

\begin{tabular}{|c|c|c|c|c|c|}
\hline Flap name & Donor site & Possible recipient sites & Pedicle & Components & Disadvantages \\
\hline $\mathrm{ALT}^{[11]}$ & $\begin{array}{l}\text { Anterolateral } \\
\text { thigh }\end{array}$ & Infraumbilical abdomen & $\begin{array}{l}\text { Descending branch of the } \\
\text { lateral femoral circumflex }\end{array}$ & Fasciocutaneous & $\begin{array}{l}\text { Limited arc of rotation } \\
\text { Flap width limited to } 8 \mathrm{~cm} \text { to permit } \\
\text { primary closure of thigh donor site }\end{array}$ \\
\hline External oblique $^{[7]}$ & $\begin{array}{l}\text { Anterolateral } \\
\text { abdominal wall }\end{array}$ & $\begin{array}{l}\text { Upper two thirds of the } \\
\text { abdominal wall }\end{array}$ & $\begin{array}{l}\text { Lateral branches of } \\
\text { posterior intercostal vessels }\end{array}$ & Myocutaneous & $\begin{array}{l}\text { Limited arc of rotation } \\
\text { Distal flap tip perfusion unreliable in } \\
\text { fasciocutaneous design }\end{array}$ \\
\hline $\operatorname{TFL}^{[8,9]}$ & Lateral thigh & $\begin{array}{l}\text { Lower two thirds of the } \\
\text { abdominal wall }\end{array}$ & $\begin{array}{l}\text { Ascending branch of lateral } \\
\text { femoral circumflex artery }\end{array}$ & Myocutaneous & $\begin{array}{l}\text { Unreliability of distal one third of } \\
\text { skin paddle }\end{array}$ \\
\hline Rectus femoris $^{[10]}$ & Anterior thigh & $\begin{array}{l}\text { Lower two thirds of the } \\
\text { abdominal wall }\end{array}$ & $\begin{array}{l}\text { Descending branch of } \\
\text { lateral femoral circumflex } \\
\text { artery }\end{array}$ & Myocutaneous & $\begin{array}{l}\text { Donor site morbidity and limited } \\
\text { terminal knee extension }\end{array}$ \\
\hline Omentum $^{[12]}$ & Omentum & Entire abdominal wall & $\begin{array}{l}\text { Right or left gastroepiploic } \\
\text { arteries }\end{array}$ & $\begin{array}{l}\text { Fat, connective } \\
\text { tissue and } \\
\text { lymphatics }\end{array}$ & $\begin{array}{l}\text { Omentum must be resurfaced with } \\
\text { a skin graft } \\
\text { Potential for intraabdominal injury }\end{array}$ \\
\hline Subtotal thigh ${ }^{[13]}$ & Thigh & Entire abdominal wall & $\begin{array}{l}\text { Lateral circumflex femoral } \\
\text { artery }\end{array}$ & $\begin{array}{l}\text { Fasciocutaneous } \\
\text { or myocutaneous }\end{array}$ & $\begin{array}{l}\text { Skin grafted donor site } \\
\text { Limited terminal knee extension } \\
\text { with inclusion of rectus femoris }\end{array}$ \\
\hline
\end{tabular}

ALT: anterolateral thighfasciocutaneous; TFL: tensor fascia lata myocutaneous
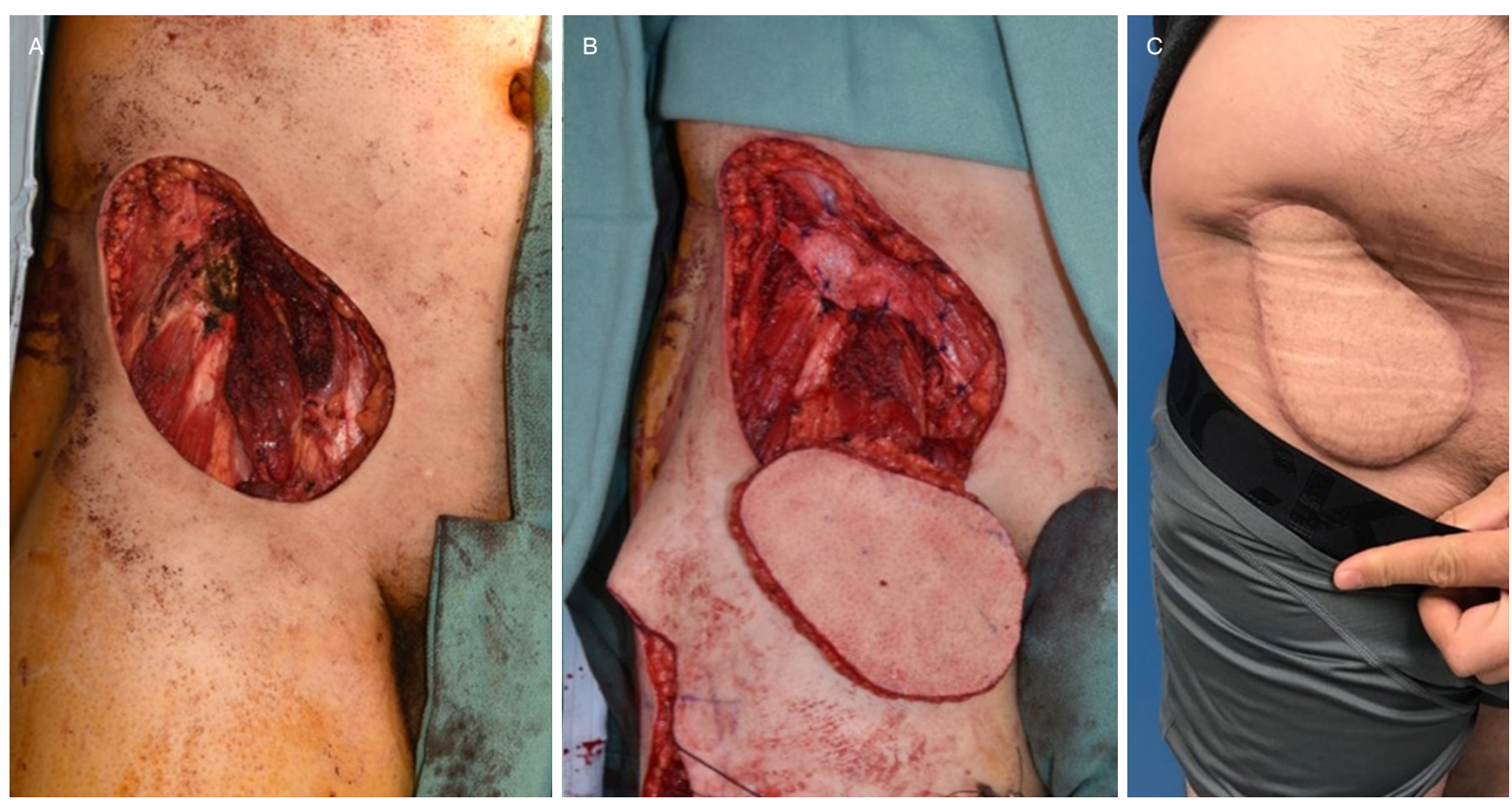

Figure 2. $9 \mathrm{~cm} \times 18 \mathrm{~cm}$ defect of right inferolateral abdominal wall with resected inguinal ligament (A). Inguinal ligament and abdominal wall reconstructed with partial underlay-bridged bioprosthetic mesh and soft tissue reconstructed with pedicled anterolateral thigh fasciocutaneous flap (B). Fully healed reconstruction six months postoperatively (C)

scenarios involving particularly large full thickness defects or in patients with many prior surgeries, a free flap may be the most optimal choice for abdominal soft tissue reconstruction [Figure 3]. Such a flap can be designed with varying size, dimension, and composition, lending more flexibility than local or regional flaps. Free flaps should be considered when local or regional flaps are not present within reach of the defect or too small to cover the defect. Most commonly, free flaps for abdominal wall reconstruction are designed from the thigh or back ${ }^{[14]}$.

In cases requiring a large skin paddle, a free flap based on the subscapular vessel system may be ideal. This particular flap can include the fasciocutaneous scapular or parascapular tissues as well as the latissimus and/or serratus anterior muscles, if a chimeric design is needed ${ }^{[15]}$. Indeed, this chimeric, conjoined 


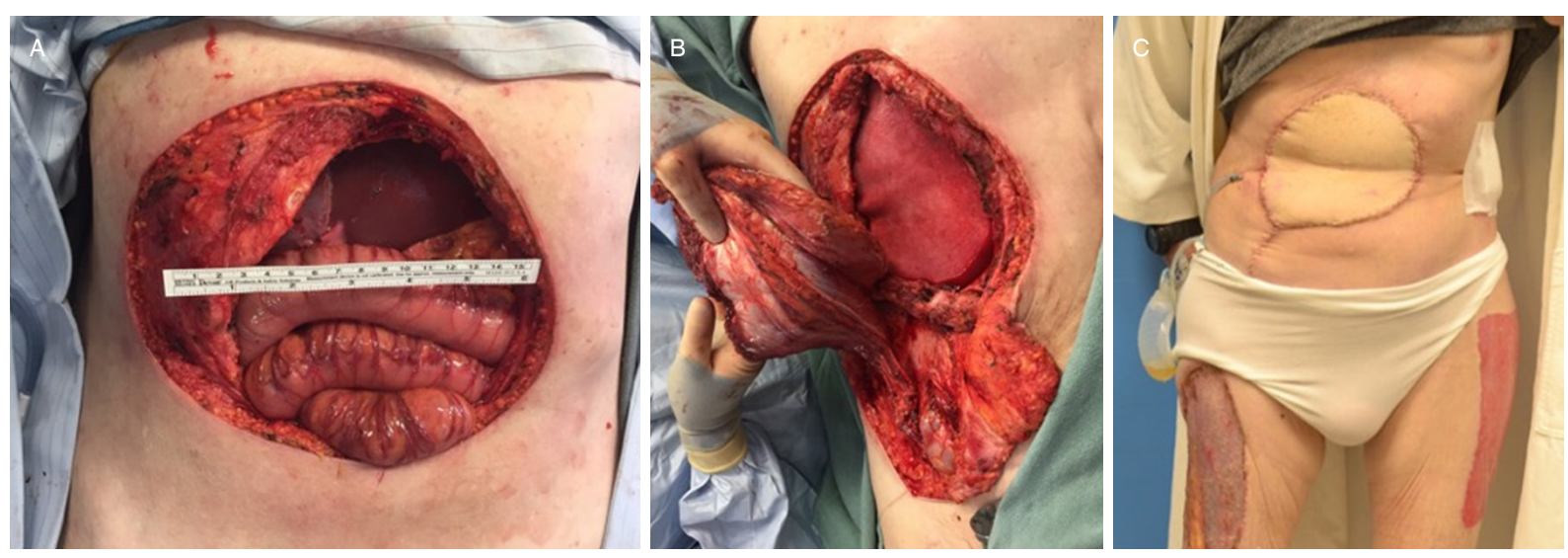

Figure $3.20 \mathrm{~cm} \times 20 \mathrm{~cm}$ full thickness defect of abdominal wall with exposed viscera (A). Myofascial defect reconstructed with a bridged bioprosthetic mesh and free anterolateral thigh myocutaneous flap anastomosed to the right deep inferior epigastric vessels (B). Healed and viable reconstruction 1 month postoperatively; anterolateral thigh flap donor site closed with skin graft (C)

flap provides well-vascularized soft tissue to resurface a defect of up to a $1500 \mathrm{~cm}^{2}$. However, it bears mentioning that if the latissimus muscle is included, donor site morbidity must be considered as it relates to the weakened abdominal wall. Patients who have decreased core muscle strength as a result of a composite abdominal wall resection will depend upon upper extremity strength and range of motion more so than is usual. Simple actions - such as rising from a seated or supine position - extensively utilize the trunk musculature. If core strength has been reduced, the upper extremities will be needed to compensate for the lack of trunk stability. Therefore, in patients requiring a large free flap, preference should be given to lowermorbidity fasciocutaneous flap options, such as the thoracodorsal artery perforator, scapular/parascapular, or fasciocutaneous subtotal thigh. In addition, if a posterior trunk flap is chosen, the patient must undergo an intra-operative position change to elevate the flap on the posterior chest wall, then another position change to supine to inset the flap. The surgeon must be aware of these logistical issues, since intraoperative repositioning adds complexity, prolongs the operative duration, and extends flap ischemia time.

The thigh represents the mainstay for free flap donor sites for the abdominal wall [Figure 3]. Pedicled thigh flaps can reach the infraumbilical abdomen, however if the defect is larger or located outside the arc of rotation, the thigh flap must be designed as a free tissue transfer. The descending branch of the lateral circumflex femoral system provides blood supply to the vastus lateralis, rectus femoris muscles and anterolateral thigh skin. The ascending or transverse branch of the lateral circumflex femoral system provides blood supply to the tensor fascia lata muscle. These flaps can be harvested as muscle only flaps or as myocutaneous flaps with overlying skin paddles. The anterolateral thigh flap is particularly versatile and can be designed with or without a segment of vastus lateralis muscle. The tensor fascia lata flap can be designed to include the distal fascia of the iliotibial tract and a smaller proximal skin paddle if needed; this fascia can be used to reconstruct the fascial component of an abdominal wall defect, providing vascularized tissue for reconstruction in lieu of mesh $^{[9,16]}$. The anteromedial thigh flap can be designed on medial perforators from the descending branch of the lateral circumflex femoral system. The rectus femoris muscle is more commonly designed as a muscle flap however a skin island can be included over the central muscle when appropriate sized cutaneous perforators are present ${ }^{[13]}$. Similar to the subscapular system, the lateral femoral circumflex vessels allow for chimeric flap design, i.e., ALT with anteromedial thigh flaps, ALT with TFL, vastus lateralis with TFL. For massive abdominal wall defects the vastus lateralis, tensor fascia lata, and the rectus femoris can be harvested with all overlying skin territory as a subtotal thigh flap for increased volume and skin coverage ${ }^{[13]}$.

Easily accessible free flap recipient vessels along the abdominal wall include the deep inferior epigastric, internal mammary, and deep circumflex iliac vessels. However, healthy recipient vessels may be absent 
or inadequate, due to injury from prior surgery, trauma, or radiation. In this situation, vein grafts can be used to increase pedicle length. Common distant recipient vessels necessitating vein grafting include the superficial femoral, descending branch of the lateral femoral circumflex, internal mammary, and thoracodorsal.

As is true for any free tissue transfer, regardless of the area reconstructed, the flap should be examined and evaluated with pencil Doppler ultrasonography every hour for the first 48-72 h. Any changes in flap perfusion warrant a return to the operating room for exploration of the microvascular anastomosis.

\section{POSTOPERATIVE CARE AND COMPLICATION MANAGEMENT}

A patient with abdominal wall reconstruction is managed similarly to a patient with any major abdominal surgery in the postoperative period. Diet is advanced in accordance with the return of bowel function, as is standard fashion. Although an abdominal binder is commonly used in cases of ventral hernia repair and abdominal wall reconstruction, a binder may be detrimental in flap cases due to the additional extrinsic pressure it transmits to the flap and vascular pedicle. Therefore, binder utilization may be delayed until the flap has developed adequate collateral circulation. Antiemetics, and if necessary, nasogastric tube decompression, are employed to minimize postoperative nausea and retching which may stress the repair. Similarly, aggressive postoperative pulmonary toilet is important to minimize coughing.

Closed-suction drains should be employed liberally for any surgery in which there is a significant amount of soft tissue undermining or dead space creation ${ }^{[2,17]}$. Postoperative prophylactic antibiotics should be considered in clean contaminated cases and/or in cases involving mesh ${ }^{[1-3]}$. Closed-incision negative pressure dressings should be considered, as they have been demonstrated to contribute to a reduced surgical site infection and surgical site occurrences rate in complex abdominal surgery ${ }^{[18]}$. We counsel all abdominal wall reconstruction patients to avoid lifting greater than $10 \mathrm{lbs}$. for 2-3 months following surgery in order to minimize hernia occurrence.

\section{CONCLUSION}

A reliable skin closure is imperative for a durable, functional, and cosmetically-acceptable abdominal wall. Depending on the defect characteristics a variety of local, regional, or free flaps are available for reconstruction of the abdominal skin and subcutaneous tissue. Each flap has inherent advantages and disadvantages, necessitating a tailored approach to each individual patient.

\section{DECLARATIONS}

\section{Authors' contributions}

Participated in the accumulation of data, literature review, writing, and editing this manuscript: Patel S, Mericli AF, Kapur SK, Roubaud MS, Butler CE

\section{Availability of data and materials}

Not applicable.

\section{Financial support and sponsorship}

None.

\section{Conflicts of interest}

All authors declared that there are no conflicts of interest.

\section{Ethical approval and consent to participate}

Not applicable. 


\section{Consent for publication}

A written informed consent for publication was obtained.

\section{Copyright}

(c) The Author(s) 2020.

\section{REFERENCES}

1. Luijendijk RW, Hop WC, van den Tol MP, de Lange DC, Braaksma MM, et al. A comparison of suture repair with mesh repair for incisional hernia. N Engl J Med 2000;343:392-8.

2. Wong A, Lee S, Nathan NS, Wang F, Hansen SL, et al. Postoperative prophylactic antibiotic use following ventral hernia repair with placement of surgical drains reduces the postoperative surgical-site infection rate. Plast Reconstr Surg 2016;137:285-94.

3. Garvey PB, Martinez RA, Baumann DP, Liu J, Butler CE. Outcomes of abdominal wall reconstruction with acellular dermal matrix are not affected by wound contamination. J Am Coll Surg 2014;219:853-64.

4. Mericli AF, Baumann DP, Butler CE. Reconstruction of the abdominal wall after oncologic resection: defect classification and management strategies. Plast Reconstr Surg 2018;142:187-96S.

5. Teo TC. The propeller flap concept. Clin Plast Surg 2010;37:615-26,

6. Mohan AT, Rammos CK, Akhavan AA, Martinez J, Wu PS, et al. Evolving concepts of keystone perforator island flaps (KPIF): principles of perforator anatomy, design modifications, and extended clinical applications. Plast Reconstr Surg 2016;137:1909-20.

7. Alexander LG, Pavletic MM, Engler SJ. Abdominal wall reconstruction with a vascular external abdominal oblique myofascial flap. Vet Surg 1991;20:379-84.

8. Tukiainen E, Leppäniemi A. Reconstruction of extensive abdominal wall defects with microvascular tensor fasciae latae flap. Br J Surg 2011;98:880-4.

9. Dorai AA, Halim AS. Extended double pedicle free tensor fascia latae myocutaneous flap for abdominal wall reconstruction. Singapore Med J 2007;48:e141-5.

10. Landim FM, Tavares JM, Costa ML, Landim RM, Feitosa RG. Complex abdominal wall reconstruction after radiation therapy: a fullthickness defect was repaired with a rectus femoris myofasciocutaneous flap. Am J Obstet Gynecol 2009;200:116.e1-3.

11. Kimata Y, Uchiyama K, Sekido M, Sakuraba M, Iida H, et al. Anterolateral thigh flap for abdominal wall reconstruction. Plast Reconstr Surg 1999;103:1191-7.

12. Manay P, Khajanchi M, Prajapati R, Satoskar R. Pedicled omental and split skin graft in the reconstruction of the anterior abdominal wall. Int J Surg Case Rep 2014;5:161-3.

13. Lin SJ, Butler CE. Subtotal thigh flap and bioprosthetic mesh reconstruction for large, composite abdominal wall defects. Plast Reconstr Surg 2010;125:1146-56.

14. Sacks JM, Broyles JM, Baumann DP. Flap coverage of anterior abdominal wall defects. Semin Plast Surg 2012;26:36-9

15. Hallock GG. The combined parascapular fasciocutaneous and latissimus muscle conjoined free flap. Plast Reconstr Surg 2008;121:101-7

16. Williams JK, Carlson GW, Dechalain T, Howell R, Coleman JJ. Role of tensor fasciae latae in abdominal wall reconstruction. Plast Reconstr Surg 1998;101:713-8.

17. Janis JE, Khansa L, Khansa I. Strategies for postoperative seroma prevention: a systematic review. Plast Reconstr Surg 2016;138:240-52.

18. de Vries FEE, Atema JJ, Lapid O, Obdeijn MC, Boermeester MA. Closed incision prophylactic negative pressure wound therapy in patients undergoing major complex abdominal wall repair. Hernia 2017;21:583-9. 